\title{
Dialysate Concentrate Device
}

National Cancer Institute

\section{Source}

National Cancer Institute. Dialysate Concentrate Device. NCI Thesaurus. Code C61403.

A reduced-volume form of the liquid that is used in a dialysis machine to carry away waste products. 